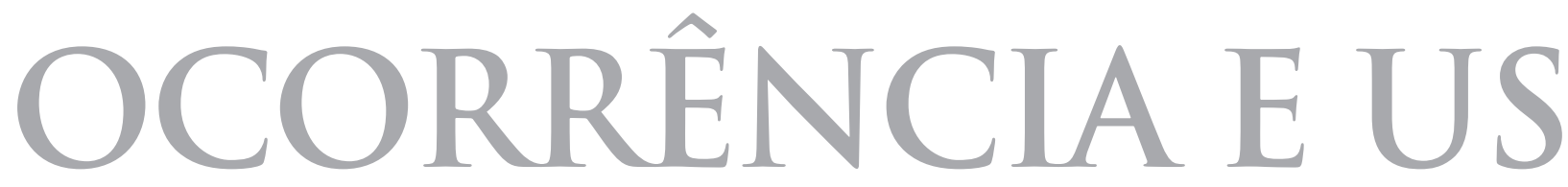

DO TUCUMÃ (ASTROCARYUM VULGARE MART COMUNIDADES RIBEIRINHAS, QUILOMBC E DE AGRICULTORES TRADICIO NO MUNICÍPIO DE IRITUIA, 


\section{OCORRÊNCIAS E USOS}

DO TUCUMÃ (ASTROCARYUM VULGARE MART.) EM COMUNIDADES RIBEIRINHAS, QUILOMBOLAS

E DE AGRICULTORES TRADICIONAIS NO MUNICÍPIO DE IRITUIA, PARÁ

\section{U CAS PERA N O V I CH I L I MA}

UNIVERSIDADE ESTADUAL PAULISTA, BRASIL

GUTEMBERG ARMANDO DINIZ GUERRA

UNIVERSIDADE FEDERAL DO PARÁ, BRASIL

\section{I N C H A U M I N G}

UNIVERSIDADE ESTADUAL PAULISTA, BRASIL

\section{MA G N O ROB ERTO A L VES MACE D O}




\title{
OCORRÊNCIA E USOS DO TUCUMÃ (ASTROCARYUM VULGARE MART.) EM COMUNIDADES RIBEIRINHAS, QUILOMBOLAS E DE AGRICULTORES TRADICIONAIS NO MUNICÍPIO DE IRITUIA, PARÁ
}

\section{Resumo}

O objetivo deste trabalho é demonstrar as ocorrências e usos do tucumã (Astrocaryum vulgare Mart.) na zona rural do município de Irituia, no Estado do Pará, uma vez que o aproveitamento da palmeira faz parte da cultura tradicional de comunidades de agricultores familiares, ribeirinhas e quilombolas, utilizada na cura de doenças, na alimentação humana e de animais domésticos, construção de abrigos, obtenção de fibras, produção de utensílios e artesanatos, caça e pesca. Além dos usos relatados pela população, o tucumã possui potencial para a produção de óleo e biodiesel. Nesse sentido, a Universidade Federal do Pará - UFPA, em parceria com a Prefeitura Municipal de Irituia, estuda a implantação de uma usina para processamento de oleaginosas no município, entre as quais se inclui o tucumã como potencial matéria prima. Esta proposta estimula a produção em sistemas agroflorestais, alternativa ao sistema de agricultura de derruba e queima, conciliando a conservação ambiental com o Desenvolvimento Rural Territorial. Considerando os resultados obtidos em trabalho de campo, podem ser estimadas em média 9,4 touceiras de tucumã por ha, cada touceira possuindo 7,7 estipes e 4,7 cachos com até 146 frutos. Se todas as touceiras de tucumã forem mantidas até que atinjam esta capacidade de produção média, estima-se que a produção de frutos na área rural do município será em torno de 132.060 toneladas, que poderão produzir até 12.665,4 toneladas/ano de óleo da polpa e 4.768,4 toneladas/ano de óleo das amêndoas, confirmando a oferta de matéria prima para movimentar essa cadeia produtiva.

Palavras-chave: agroextrativismo, oleaginosas, agricultura tradicional, saberes locais, desenvolvimento sustentável.

\section{OCCURRENCE AND USES OF TUCUMÃ (ASTROCARYUM VULGARE MART.) IN RIVERINE, QUILOMBOLA AND TRADITIONAL FARMERS IN THE MUNICIPALITY OF IRITUIA- STATE OF PARÁ, BRAZIL}

\begin{abstract}
The aim of the study is to demonstrate the occurrence and usage of the Tucumã (Astrocaryum vulgare Mart.) in rural areas of the Municipality of Irituia, in the State of Para (Brazil), since the use of the palm part of the traditional culture of communities of farmers, riparian and quilombola, used in curing diseases in human and domestic animals, building shelters, obtaining fibers, production of tools and crafts, hunting and fishing. In ad-
\end{abstract}


dition to the uses reported by the population, tucumã has potential for the production of oil and biodiesel. In this sense, the Federal University of Pará - UFPA, in a partnership with the Irituia's Municipal Government, is studying the implementation of an oleaginous processing plant in the municipality, among them, and includes the Tucumã as a potential source. Such proposal stipulates the production in the agroforestry system, as an alternative to the slash and burn agriculture in the region, reconciling environmental conservation with territorial rural development. Considering the results obtained in the field, it has been found an average of 9.4 stumps per hectare, each stump having 7.7 stipes and 4.7 racemes with up to 146 fruits. If all the Tucumã's stumps were kept until they reached their average productivity capacity, it is estimated that the fruit production in the rural area of the municipality would be around 132.060 tons, which could produce up to $12.665,4$ tons/year of pulp oil and $4.768,4$ tons/year of nut oil, confirming the supply of raw material to move this productive chain.

Keywords: agro-exploration, oleaginous, traditional agriculture, local knowledge, sustainable development.

\section{OCCURRENCE ET USAGES DU TUCUMÃ (ASTROCARYUM VULGARE MART.) EN COMMUNAUTES RIVERAINES, QUILOMBOLAS ET DES AGRICULTEURS TRADITIONNELS DANS LA MUNICIPALITE D'IRITUIA, PARA}

\section{Résumé}

Le sujet de cet article est demontrer l'ocurrence et les usages du tucumã ( $A s$ trocaryum vulgare Mart) dans la zone rurale du municipe d'Irituia, dans l'État du Pará, une fois que le profit de ce palmier fait partie de la culture traditionnelle des communautés des agriculteurs familiaux, des riverains et des descendents des esclaves. Ce palmier est aussi utilisé comme medicine pour maladies, dans l'alimentation humaine, comme nourriture pour des animaux doméstiqués, pour la construction des logements, pour l'obtention de fibres, pour la production d'outils et l'artisanat, pour la chasse et la pêche. Plus que des usages indiqué par la population locale, le tucumã a le potentiel pour la production d'huile de palme et le biodiesel. Dans ce sens, l'Université Fédérale du Pará - l'UFPA, en partenariat avec la Mairie d'Irituia, a promu des études pour l'implantation d'une usine pour la transformation des oleagineuses existentes dans le territoire de la municipalité, entre lesquelles s'est inclu le tucumã comme potentielle matière première. Cette proposition incite la production des sistèmes agroforestières comme une alternative au sistème d'abbatis-brûlis, en conciliant la conservation environementale avec le Développement Rural Territorial. Aprés les mensurations sur le terrain, on peut estimer une moyenne de 9,4 souches de tucumã par hectare, chaque souche avec 7,7 estipes et 4,7 regimes avec jusqu'à 147 fruits dans chaque regime. Si toutes les souches de tucumã restent maintenus jusqu’à atteindre cette moyenne de production, 
on estime que la production totale d'Irituia serait au tour de 132060 tones, qui pourraient être transformé en 12 665,4 tones/année de huile de la pulpe et 4768,4 tones/année de huile des amandes, ce qui confirmerait la matière première pour mouvementer toute cette chaine de production.

Mot-clés: agroextraction; oleagineuses; agriculture traditionelle; savoirs locaux; développement durable.

Endereço do primeiro autor para correspondência: Faculdade de Ciências Agronômicas, Universidade Estadual Paulista - Fazenda Lageado. Portaria I: Rua José Barbosa de Barros, no 1780 - CEP: 18.610-307 - Botucatu, SP, Brasil.E-mail: lpelima@gmail.com 


\section{AGRICULTURA CAMPONESA EM BUSCA DE ALTERNATIVAS}

A agricultura é uma das principais atividades econômicas das comunidades camponesas da Amazônia, que emprega grande volume de mão de obra, gera importantes recursos financeiros e movimenta complexos sistemas de relações sociais e culturais, além de ser um dos principais agentes transformadores (ou organizadores) da paisagem (Pereira et al. 2006).

$\mathrm{Na}$ região nordeste paraense, os sistemas de cultivo típicos da agricultura tradicional são caracterizados pela agricultura de derruba e queima, caráter familiar da produção e autoconsumo. Para Pereira et al. (2006) esse tipo de manejo é o que tem possibilitado a reprodução das famílias ao longo de centenas de anos causando impactos mínimos na cobertura florestal, quando comparados aos sistemas de produção especializados e de larga escala como a cana, soja, algodão, café e a pecuária bovina.

Os sistemas de produção de comodities desconsideram a gestão e aproveitamento dos recursos naturais. Sampaio et al. (2008) defendem que a geração de tecnologia do corte e trituração da capoeira sem queima aponta os caminhos capazes de garantir a segurança das comunidades locais, impedindo a deterioração dos ecossistemas e a degradação humana. De acordo com o mesmo trabalho, a incorporação da matéria orgânica produzida pela capoeira e produção agroflorestal tem mostrado bons resultados na região, como a fertilização dos solos, aproveitamen- to intensificado das áreas e melhorias no rendimento familiar e qualidade de vida.

No município de Irituia, alguns agricultores resolveram inovar e experimentar novos arranjos produtivos, valorizando produtos regionais e expandindo seus quintais florestais para outras parcelas de seus agroecossistemas, roças, capoeiras e mata ciliar, denominandoos de sítios, que na bibliografia acadêmica do campo das ciências agrárias, tem sido denominado de Sistemas Agroflorestais - SAF (Oliveira et al. 2007).

Essa nova forma de pensar e de fazer agricultura despertou o interesse de instituições governamentais e não governamentais, permitindo a inserção do município de Irituia no Programa de Desenvolvimento Socioambiental da Produção Familiar Rural na Amazônia - PROAMBIENTE que faz parte das políticas públicas da pasta do Ministério do Meio Ambiente do Governo Federal que objetivou compatibilizar a conservação ambiental com o processo de desenvolvimento rural (Oliveira et al. 2007).

Através de incentivos do Programa PROAMBIENTE Pólo Rio Capim, da Secretaria Municipal de Agricultura - SEMAGRI e da experiência de agricultores familiares inovadores, tem-se evidenciado o papel das agroflorestas na segurança alimentar de Irituia. Além disso, a atividade integra-se às medidas de preservação ambiental, deixando de lado a agricultura itinerante para a utilização de um sistema mais complexo e menos instável pela presença de cultivos permanentes.

No município, existem agroflorestas 
desenvolvidas, como na cultura do açaí com outras espécies nativas, áreas de pastagens e cultivo de mandioca, além de caju, tucumã, inajá, entre outras que nascem espontaneamente em áreas de regeneração natural e contribuem para o sustento das famílias, contando apenas com o banco de sementes existente no solo. A vegetação secundária dessa região compreende espécies frutíferas, medicinais e oleaginosas. As espécies que mais demonstram potencial extrativista para extração de óleo são: as palmeiras (Arecaceae), tucumã (Astrocaryum vulgare Mart.), muru-muru (Astrocaryum murumuru Mart.), inajá (Maximiliana maripa L.), buriti (Mauritia flexuosa L.) e marajá (Bactris maraja Mart.).

Com a pretensão de explorar esta riqueza como medida socioambiental, a Prefeitura Municipal de Irituia, apoiada pela Universidade Federal do Pará - UFPA estuda a possibilidade da implantação de uma usina de oleaginosas no município de Irituia, sendo o tucumã, a principal matéria prima desta produção.

Observa-se a presença desta espécie em toda a microrregião, porém não há estudos que quantifiquem a produção do tucumã que permitam a implantação de uma usina de beneficiamento de oleaginosas. Nesse sentido, o objetivo deste trabalho é de estimar a produção do tucumã na zona rural do município de Irituia, a partir da observação e conhecimento dos agricultores, para uma avaliação da possibilidade de seu aproveitamento industrial. Além disso, foram levantadas as formas de usos tradicionais feitos pelas comunidades de agricultores, ribeirinhos e quilom- bolas como forma de provar a influência do tucumã do Pará na cultura tradicional da Amazônia.

\section{O TUCUMÃ NA LITERATURA CIENTÍFICA E NO CAMPO DE IRITUIA}

O município de Irituia possui área aproximada de $1.380 \mathrm{~km}^{2}$ e população com 30.552 habitantes (IBGE 2009). Localiza-se na mesorregião do nordeste paraense, área de colonização mais antiga da Amazônia Oriental brasileira, a $170 \mathrm{~km}$ da capital do Estado, Belém. Limita-se ao norte com o município de São Miguel do Guamá, ao sul com o município de Mãe do Rio, ao leste com Capitão Poço e ao oeste com São Domingos do Capim (Valente et al. 2001).

Segundo dados do Censo Agropecuário de 2006, a economia do município é basicamente agrícola, com cerca de $70 \%$ de sua área total 100.000 ha) ocupada pelos estabelecimentos agropecuários, sendo 17.525 ha destinados à exploração agroflorestal (IBGE 2006). A cobertura vegetal original é fragmentária em decorrência da histórica exploração madeireira e expansão da ocupação destinada a pastagens e agricultura itinerante. As florestas secundárias, denominadas regionalmente de capoeira, respondem por $90 \%$ de toda a cobertura vegetal do município (Valente et al. 2001; Schwartz 2007).

Como na região em que se encontra, o município de Irituia abriga comunidades remanescentes de camponeses tradicionais, ribeirinhas e quilombolas, que há séculos usufruem da bio- 
diversidade encontrada nas matas, nas capoeiras e nos rios, produzindo conhecimentos e um modelo de vida próprio, que vem sendo transmitido de geração em geração. Essas comunidades rurais são descritas por Nahum (2011) como sendo possuidoras de grande capacidade de resistência e criatividade, que permitiu suportar o período dos engenhos e olarias, alicerçados numa dinâmica territorial profundamente desigual e, até hoje, esquecidos pelo poder público.

Nesse contexto se insere o tucumanzeiro ou tucumã do Pará (Astrocaryum vulgare Mart.), cuja utilização está relacionada aos costumes e ao modo de vida dos povos tradicionais da Amazônia Oriental, relacionadas à cura de doenças, a alimentação humana e de animais domésticos, a construção de abrigos, a obtenção de fibras, a produção de utensílios e artesanatos, a caça e pesca.

O tucumã é mencionado como uma das palmeiras importantes para a região Amazônica, porém poucos estudos têm sido realizados no sentido de contribuir para a sua domesticação (Lima et al. 1986). Apesar de ter grande potencial para a produção de óleo, semelhante ao dendezeiro (Elaeis guineensis Jacq.), e ser excelente fonte de vitamina $\mathrm{A}$, o uso do tucumã ainda se restringe ao autoconsumo das comunidades rurais e urbanas de baixa renda.

O tucumã do Pará é uma palmeira de cultura pré-colombiana, de ampla distribuição na Amazônia Oriental, onde está localizado um dos importantes centros de diversidade do gênero $A s$ trocaryum (Lleras et al. 1983). A espécie floresce entre março e julho e frutifica na época chuvosa, ou seja, de janeiro a abril. Contudo, se bem manejada, essa palmeira pode dar frutos durante todo o ano (Cymerys 2005).

Cymerys (2005) relata a dificuldade em estudar a densidade populacional do tucumanzeiro, pois sua distribuição se dá na forma de "manchas" (várias plantas juntas) podendo não ser encontrado por vários hectares, bem como em concentrações com mais de 50 palmeiras em um único hectare.

Lima (1986) afirma que podem ser encontrados exemplares precoces em que o cacho da primeira inflorescência brota abaixo do solo, nas axilas de folhas novas e, em outras plantas em condições idênticas as primeiras inflorescências ocorrem apenas ao atingir 3,5 $\mathrm{m}$ de altura do estipe.

O tucumanzeiro produz de 2 a 3 cachos anualmente, podendo chegar a mais de 5, possuindo peso médio de 10 a 30 quilos cada, com produção de frutos que podem chegar de 200 a 400 frutos, produzindo cerca de 50 quilos de frutos por ano, mesmo em solos pobres (Cymerys 2005). Em estudos sobre a potencialidade agroindustrial do tucumã, Lima et al (1986) encontrou exemplares com o número máximo de 13 cachos por estipe e cachos maiores que $2 \mathrm{~m}$ de comprimento possuindo até 568 frutos por cacho.

Costa et al. (2010) avaliaram as características dos cachos em 125 plantas de tucumã do Banco de Germoplasma da Embrapa Amazônia Oriental. Segundo os resultados deste estudo (Tabela 1), 
um cacho de tucumã produz cerca de 4,03 quilos de frutos, o que corresponde a uma produção média de 149 frutos.

Assim como ocorre com a palmeira africana do dendê (Elaeis guineensis Jacq.), é possível obter dois tipos de óleo dos frutos do tucumã: um a partir da polpa e outro das amêndoas, ambos comestíveis, porém de qualidades diferentes (Pesce 2009). Segundo Pesce (2009), a polpa do tucumã produz um óleo de cor alaranjada, fazendo com que seu uso na culinária, seja o mesmo do azeite de dendê, com alto teor de ácidos graxos e consistência de vaselina em temperatura inferior a $27^{\circ} \mathrm{C}$. $\mathrm{O}$ óleo das amêndoas é mais valorizado, possui coloração branca e baixa acidez, o que torna o refino muito simples e pouco dispendioso. A qualidade deste óleo é semelhante ao óleo da amêndoa da palmeira africana, especialmente adequado para usos comestíveis, apresentando ponto de fusão em $30^{\circ} \mathrm{C}$.

Segundo Rogerio et al. (2010) o rendimento da polpa do tucumã é de 53,88\%, com taxa média de umidade de 52,4\% e rendimento de óleo de $37,41 \%$ a partir do extrato seco e 17,8\% a partir do material fresco. Foi observada elevada concentração de ácidos oléicos, com média de 70,7\%, comparável ao azeite de oliva. $\mathrm{O}$ rendimento das amêndoas é de $17,7 \%$, possuindo umidade média de $22,7 \%$. O rendimento médio de óleo na amêndoa foi de 26,3\% no material seco e 20,4 no material úmido (Rogerio et al. 2010). Miranda \& Rabelo (2008: 113-117) afirmam que o óleo de tucumã é valorizado por sua utilização na indústria cosmética como matéria prima no preparo de sabões e medicamentos para o tratamento de furúnculos e dor de dente. A espécie também tem se mostrado promissora na produção do biodiesel da Amazônia. No trabalho de Lima et al. (2001) o uso do óleo de tucumã extraído artesanalmente, embora necessite de cuidados quando do processo de purificação, apresentou resultados satisfatórios e condições viáveis para a obtenção de biodiesel. As características do biodiesel de tucumã como a viscosidade, ponto de fulgor e densidade refletem claramente esta viabilidade.

Por se tratar de uma espécie de ocorrência espontânea em áreas de regeneração natural, a exploração do tucumã é basicamente agroextrativista ou extrativista, apresentando-se como oportunidade estratégica para o desenvolvimento sus-

Tabela 1

Médias, valores mínimos, valores máximos e coeficientes de variação para as características do cacho de tucumã (Astrocaryum vulgare Mart.)

\begin{tabular}{lcccc}
\hline \multicolumn{1}{c}{ Caracteres } & Média & V. mínimo & V. máximo & CV $(\%)$ \\
\hline Peso total do cacho $(\mathrm{kg})$ & 4,39 & 0,7 & 17 & 59,2 \\
Peso total de frutos por cacho $(\mathrm{kg})$ & 4,03 & 0,5 & 16,6 & 62,81 \\
Peso de dez frutos $(\mathrm{g})$ & 269,9 & 100 & 600 & 35,36 \\
\hline
\end{tabular}

Fonte: Costa et al. (2010). 
tentável em comunidades tradicionais do município de Irituia, a partir de melhorias no rendimento familiar, incentivo à conservação da biodiversidade local e a valorização da identidade das populações tradicionais. Nesse sentido, iniciativas que venham a desenvolver a cadeia produtiva do tucumã na região, vão ao encontro da proposta do Plano Nacional de Promoção das Cadeias de Produtos da Sociobiodiversidade, que tem por objetivo o fortalecimento das atividades agroextrativistas em comunidades tradicionais (Brasil 2009)

\section{MENSURAÇÕES E ESTIMATIVAS DO TUCUMÃ EM IRITUIA: PROCEDIMENTOS METODOLÓGICOS}

A pesquisa de campo foi realizada entre agosto e outubro de 2010 no município de Irituia, quando foram visitados 44 estabelecimentos e realizadas 58 entrevistas com agricultores de ambos os sexos e idades que variam entre 18 e 96 anos. A disparidade entre o número de entrevistados e propriedades se deve ao fato de que familias independentes residem e trabalham na mesma propriedade rural.

A escolha dos estabelecimentos para a entrevista ocorreu por indicação de lideranças dos bairros visitados com o apoio da Secretaria Municipal de Agricultura. No questionário aplicado, foram levantadas as informações sobre os estabelecimentos familiares, incluindo idade, número de pessoas que vivem no estabelecimento, sistema produtivo, área total, existência de tucumã dentro e fora de áreas de SAFs, estimativa do número de tucumanzeiros no estabe- lecimento, estimativa do número de perfilho em uma touceira, estimativa do número de cachos por estipe, estimativa do número de frutos por cacho, usos gerais do tucumã e tipos de comercialização.

Dada a extensão territorial do município (138 mil ha), com distância considerável entre a sede do município e as comunidades, para realizar as entrevistas foi necessário articular encontros, através da Secretaria Municipal de Agricultura, com as associações ou agricultores de cada comunidade, agendando visitas em seus estabelecimentos e de seus vizinhos. O deslocamento para acessar as comunidades rurais foi feito a pé, em bicicletas, motocicletas e automóveis.

As informações sobre o uso, produção e rendimento do óleo do tucumã, foram baseadas nos estudos de Costa et al. (2010) e Rogerio et al. (2010) e relacionadas às informações coletadas nas entrevistas individuais semiestruturadas, observação in loco, georreferenciamento dos estabelecimentos dos entrevistados, realização de fotografias, gravação de conversas induzidas sobre o tucumã, anotações em caderno de campo e tabulação utilizando-se o programa Microsoft Excel.

Para o georreferenciamento dos estabelecimentos foi utilizado aparelho GPS Global Positioning System, de fabricação da Garmin, no modelo V. As informações obtidas a partir do GPS foram inseridas no Software de manipulação de informações geográficas GPS Trackmaker PRO, para a construção da Carta Imagem que espacializou o levantamento de campo. Este documento cartográfico foi referenciado ao sistema 
de coordenadas UTM SIRGAS 2000, zona 23, com vistas à sobreposição das informações de campo em imagem do satélite Spot-5. Para tal adaptação foi utilizada a imagem Spot HX0 de 13/07/2008 cenas 57043532/42/52 cedidas pelo IDESP (2010). Na Figura 1 , pode-se verificar a plotagem dos pontos de ocorrência do tucumã no Município de Irituia. Eles estão representados pelos círculos brancos legendados como estabelecimentos e os retângulos representam as comunidades.

Os dados foram tabulados e analisados mediante diálogo com a literatura pertinente sobre o tucumã, estimando-se a produção média do município pela comparação entre os dados do volume de produção com a área do município, tecendo considerações e fazendo-se inferência possível sobre os usos e potencialidades deste recurso natural presente no município.

\section{O TUCUMÃ E SUAS POSSIBILIDADES: RESULTADOS E DISCUSSÃO}

Foi observado que o tucumã é uma planta de presença espontânea, ocorrendo em todos os ecossistemas de terra firme, desde vegetações primárias, secundárias (capoeiras) e pastagens abandonadas de solos degradados.

A área total atendida nos estabelecimentos visitados foi 2.113 hectares o que corresponde a 2,1\% da área total de estabelecimentos agropecuários de Irituia, distribuídos em 15 comunidades de agricultores tradicionais, ribeirinhos e quilombolas denominadas como: Açaiteua, Araraquara, Boa
Vista, Borges, Galiléia, Irituia, Lago, Retiro, Maracaxeta, Nova Laudicéia, Pinheiro, Providência, Puraquequara, Santa Cruz e São Francisco do Itabocal.

Em todos os estabelecimentos entrevistados, pode-se observar a existência do tucumã, porém a maioria dos agricultores considera a espécie como uma planta daninha, pois nasce em meio à roça e dificulta o trabalho ao redor da touceira devido à quantidade de espinhos que possui na parte superior do caule.

Segundo o relato dos agricultores entrevistados, o lenho do estipe é muito duro e os espinhos impedem o corte com ferramentas manuais, desse modo os agricultores optam por eliminar as touceiras utilizando o arranque por máquinas. É comum o uso do fogo, que se espalha pela touceira rapidamente, mas geralmente em poucos dias ocorre a rebrota de novos estipes, por isso a planta é considerada resistente às chamas, visto que o fogo consume partes, porém não elimina as touceiras. Para extinção da planta, a técnica utilizada é a aplicação de óleo queimado, o que elimina a possibilidade de rebrota. A disseminação da planta é muito eficaz, pois produz muitos frutos que servem de alimento para animais domésticos e silvestres, que espalham as sementes pelo campo.

Nas visitas, foi observado que a densidade e a altura dos estipes por touceiras dependem do sistema em que estão inseridas, pois dentro de uma vegetação primária ou secundária em estádio de sucessão avançado, ocorrem plantas de tucumazeiros com até três estipes bem desenvolvidos, podendo passar de $25 \mathrm{~m}$ de altura. Em pastagens de- 


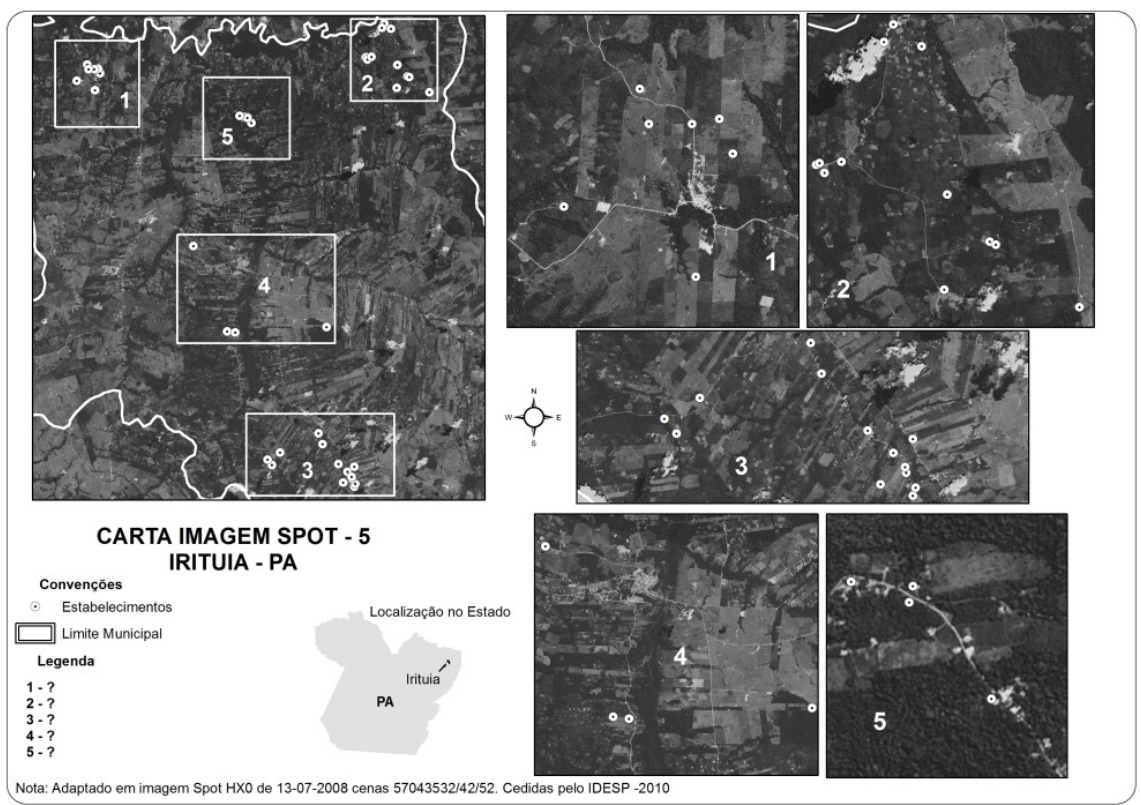

Figura 1 - Ocorrência de Tucumã em estabelecimentos e localidades do Município de Irituia. Fonte: Entrevista aplicada no Município de Irituia - 2010).

gradadas foram encontradas touceiras com mais de 20 estipes, apresentandose muito mais volumosos e com altura bastante reduzida.

O tucumã do Pará é cultivado por 36\% dos entrevistados em Sistemas Agroflorestais. Entre eles, 9,5\% plantaram suas mudas a partir de tucumanzeiros selecionados, com os melhores aspectos de tamanho e sabor dos frutos. Para os outros 64\% dos entrevistados, a ocorrência das touceiras de tucumã acontece espontaneamente em pastagens, capoeiras ou roças.

A média da área dos estabelecimentos entrevistados foi de 48,02 ha. Seus moradores estimaram a quantidade de touceiras de tucumãs em seus estabelecimentos (Tabela 2) e relataram suas observações sobre o uso, costumes e produção do tucumanzeiro, como número de estipes, cachos e frutos.

Considerando a média da área dos estabelecimentos entrevistados e número médio de touceiras de tucumã por propriedade, tem-se a média de 9,38 touceiras por ha. De acordo com o IBGE (2006), a área total de estabelecimentos agropecuários em Irituia é de 98.663 ha, totalizando 925.458,9 touceiras de tucumã. Com base nestes dados, estima-se a capacidade de produção no município em 4.892.933.822 frutos.

Os resultados obtidos nos estudos de Costa et al. (2010) e Rogerio et al. (2010) geram parâmetros para estimar a produção de óleo a partir da polpa e amêndoas do tucumã, apresentado na Tabela 3. 
Tabela 2

Estimativa de ocorrência e produção do tucumanzeiro

\begin{tabular}{lcccc}
\hline \multicolumn{1}{c}{ Características da planta } & Média & V. mín. & V. Max. & CV (\%) \\
\hline Número de touceiras por propriedade (unid.) & 450,4 & 4 & 3000 & 136,6 \\
Número de estipes por touceira (unid.) & 7,7 & 3 & 20 & 66,99 \\
Número de cachos por estipe (unid.) & 4,7 & 3 & 6 & 18,56 \\
Número de frutos por cacho (unid.) & 146,1 & 50 & 500 & 69,32 \\
\hline
\end{tabular}

Fonte: Entrevista aplicada no Município de Irituia (2010).

Tabela 3

Estimativa da produção total de polpa, amêndoas e seus respectivos óleos, na área total de estabelecimentos agropecuários do município de Irituia.

\begin{tabular}{lc}
\hline \multicolumn{1}{c}{ Produção } & Valor estimado \\
\hline Peso total de frutos $(\mathrm{t})$ & $132.060,28$ \\
Produção de polpa $(\mathrm{t})$ & $71.154,08$ \\
Produção de óleo da polpa (t) & $12.665,42$ \\
Produção de amêndoas (t) & $23.374,67$ \\
Produção de óleo de amêndoas (t) & $4.768,43$
\end{tabular}

Fonte: Entrevista aplicada no Município de Irituia (2010).

As plantas de tucumã que foram contabilizadas durante as entrevistas incluem brotações indesejadas em pastagens e roças, que periodicamente sofrem tentativas de serem eliminadas principalmente pela utilização do fogo. Este fato impede que estas plantas atinjam a produtividade que teriam em condições normais. Por outro lado, a perspectiva de beneficiamento industrial poderá induzir à preservação e intensificação do cultivo desta espécie, superando as estimativas feitas neste estudo. Para atingir à produção estimada de frutos seria necessário que as touceiras de tucumã sejam mantidas no campo até que tenham capacidade de alcançar os níveis de produtividade esperados. Mesmo nessas condições, $86 \%$ dos entrevistados não vê retorno satisfatório na produção de tucumã.

Os dados da Tabela 3 mostram que existe matéria prima para industrialização do tucumã, como a produção do óleo, biodiesel, polpas, amêndoas, entre outros produtos, porém, enquanto esta cadeia produtiva não é impulsionada por iniciativas públicas ou privada, o uso do tucumã permanece limitado ao aproveitamento tradicional e de autoconsumo.

A palmeira do tucumã possui diversas utilidades no cotidiano dos moradores de comunidades ribeirinhas, quilombolas e agricultores tradicionais, o que se verificou nas entrevistas realizadas em Irituia.

O fruto é valorizado na alimentação, tendo sido informado por $90 \%$ dos entrevistados que os consomem tanto in natura, quanto misturados com farinha 
de mandioca (mingau de farinha), fervido (vinho), como suco ou creme. Para que a polpa do tucumã fique mole e saborosa, os agricultores utilizam a técnica que consiste em cortar o cacho inteiro e enterrar por três dias.

Existem formas menos comuns de uso do tucumã na alimentação, como desenterrar os cocos recém-germinados para comer a amêndoa, que nesta fase se encontra com o aspecto poroso como uma maçã e com sabor adocicado; o palmito é retirado de plantas novas, enquanto o lenho ainda é flexível; algumas pessoas costumam beber a água ou comer a massa do fruto verde, que se assemelha à água e à massa do coco verde baiano (Cocos nucifera L), ou ainda na forma de "café de tucumã" em que as amêndoas são torradas, socadas em pilão e depois coadas como café.

O tucumã é muito utilizado na alimentação animal: $71 \%$ dos entrevistados colhem os frutos para alimentar principalmente suínos e aves. Segundo relato dos entrevistados, os animais engordam rapidamente por se tratar de um alimento altamente calórico e, no caso das aves, confere uma coloração amarelada à carne, aspecto considerado positivo para o consumo. Após o mês de abril, quando os frutos estão escassos, alguns criadores de suínos juntam cocos e os fornecem quebrados para que os animais se alimentem das amêndoas.

O estipe do tucumã é utilizado por $26 \%$ dos entrevistados como esteio, madeira para a construção de casas rústicas, currais ou mourão de cerca. A madeira é descrita por eles como muito rígida e, quando protegida da ação da chuva, possui durabilidade estimada em vinte anos, mas quando exposta às intempéries, a durabilidade diminui pela metade.

Para os entrevistados, o uso medicinal do tucumã não está relacionado diretamente ao fruto, mas às larvas de besouro (Coleoptera) conhecidas popularmente como "tabaruá" ou "broca do tucumã" e encontradas dentro dos cocos envelhecidos. Estas larvas são coletadas e levadas ao fogo em uma panela de maneira que, ao fritarem, liberam um óleo, que segundo $21 \%$ das pessoas entrevistadas, pode ser usado contra asma, inchaço, luxações, contusões, derrame, reumatismo e picadas de formigas-tucandeiras (Paraponera clavata F.).

Outras utilizações da "broca do tucumã" foram citadas em 33\% das entrevistas, envolvendo a alimentação humana e animal. Lima (1986) e Cymerys (2005) afirmam que as larvas possuem alto valor nutritivo e calórico, podendo ser consumidas cruas, fritas ou assadas. Na pesca, a "broca" é utilizada como isca para traíra, aracu, jundiá, piaba e camarão.

A utilização do tucumã para a confecção de artesanatos foi citada por $24 \%$ dos entrevistados. Pescadores utilizam os talos das folhas das palmeiras de tucumã para fazer camaroeiros, matapís e cacurís, armadilhas para captura de camarões e peixes. Eles explicaram que esses objetos podem ser feitos utilizando-se folhas de outras palmeiras, porém a que garante maior resistência é a do tucumã. Os cocos do tucumã também são utilizados na 
confecção de biojoias, como brincos, anéis, colares e pulseiras.

Sobre a comercialização do tucumã, $14 \%$ das pessoas entrevistadas referem esta prática, seja na forma de fruto in natura, polpa ou artesanato. A venda de frutos in natura (9\%) ocorre geralmente em feiras livres, pelo preço de $\mathrm{R} \$ 0,10$ / unidade. O comércio de polpas $(3 \%)$ costuma ser destinado às sorveterias, vendido a $\mathrm{R} \$ 7,00 / \mathrm{Kg}$ direto nas fábricas ou para atravessadores pelo preço de $\mathrm{R} \$ 2,00 / \mathrm{Kg}$.

A procura por bijuterias produzidas a partir de produtos naturais tem aumentado em Irituia e outras regiões do Brasil, ampliando as possibilidades de agregar valor aos produtos extrativos. $\mathrm{O}$ preço pago ao artesão varia de $\mathrm{R} \$$ 5,00 a R \$ 15,00 por peça (anel, colar, brinco, pulseira, bracelete). Apenas uma pessoa entre as 58 entrevistadas, se dedica a esta atividade e diz não conseguir atender à demanda.

Somente 3\% das pessoas entrevistadas afirmam não utilizar o tucumã em nenhuma das atividades referidas neste trabalho, ainda que possuam muitas plantas em seus estabelecimentos.

Todos os entrevistados afirmam que existem diferenças entre os tucumanzeiros, tanto no formato, quanto na qualidade e proporção mesocarpo/ endocarpo dos frutos. Existem frutos doces e outros pouco adocicados chamados popularmente de "secos" ou "salobros". Podem possuir cocos pequenos com bastante polpa ou cocos grandes com pouca polpa. O formato varia entre redondo e oval.
Essas características comprovam a existência de variedades da espécie, reforçando a necessidade do estudo visando o melhoramento vegetal aumentando a produtividade e melhor apropriação desta espécie.

\section{CONSIDERAÇÕES FINAIS}

As diversas características do tucumã tornam promissora à sua participação nos arranjos de Sistemas Agroflorestais da região, mas sua utilização ainda é pequena, principalmente pela falta de conhecimento preciso sobre a produção municipal, incipiente mercado consumidor $\mathrm{e}$ falta de estímulos para a comercialização, de tal forma que o uso da planta fica restrito para o suprimento das necessidades da família.

Os usos mais comuns dos frutos são na alimentação humana e na alimentação animal, a larva do coleóptero encontrado nas amêndoas para a preparação de óleo medicinal, os troncos são utilizados como estacas ou esteios e folhas e endocarpo na confecção de cestarias e artesanato.

Baseando-se nas estimativas de produção de cada estabelecimento entrevistado, o estudo revelou a potencialidade de produção em Irituia de 12.665,4 toneladas de óleo de polpa e 4.768,4 toneladas de óleo das amêndoas do tucumã por ano, o que pode ser considerada uma produção significativa, para que se implante a usina proposta.

Frente à capacidade produtiva do tucumã e considerando sua plena distribuição no município de Irituia, pode se afirmar que há matéria prima, com 
baixo custo de produção, para a atividade de extração de óleo, e que vem sendo desperdiçada. Porém, são necessários estudos para avaliar as variedades do tucumã quanto ao teor de óleo e produção de frutos, a fim de selecionar as plantas mais produtivas, além de estudos aprofundados sobre outras espécies de oleaginosas como o Inajá (Maximiliana maripa L.) e o Muru-muru (Astrocaryum murumuru Mart.) que permitam complementar a produção de oleaginosas a ser processada pela usina.

A implantação de uma usina de oleaginosas no município é uma oportunidade de mudança nos sistemas produtivos e na economia da agricultura familiar local, contribuindo para o aumento da renda monetária da família e no aproveitamento de um recurso natural desenvolvimento sustentável.

Considerando a importância desta planta nos usos cotidianos das populações estudadas e o que vem referido na literatura pertinente ao assunto, o estímulo à sua preservação e uso recomenda investigação.

\section{REFERÊNCIAS}

Brasil. 2009. Plano Nacional de Promoção das Cadeias de Produtos da Sociobiodiversidade - PNPSB. Brasília: Ministério do Desenvolvimento Agrário - MDA, Ministério do Meio Ambiente - MMA, Ministério do Desenvolvimento Social e Combate a Fome - MDS.

Costa, D. L.; M.S.P. de Oliveira \& B.O.A. de Souza. 2010. Avaliação de caracteres de cachos em acessos de tucumã (Astrocaryum vulgare Mart). $14^{\circ}$ Seminário de Iniciação Cientí- fica da Embrapa. Belém: Embrapa AmazÔnia Oriental.

Cymerys, M. 2005. Tucumã do Pará, in Frutiferas e plantas uteis na vida Amazônica. Editado por P. Shanley \& G. Medina, pp. 209-214. Belém: CIFOR, Imazon.

IBGE. Instituto Brasileiro de Geografia e Estatística. 2010. Estimativas das populações residentes, em $1^{\circ}$ de julho de 2009. Disponível em: http://www.ibge.gov.br/ home/estatistica/populacao/estimativa2009/POP2009_DOU.pdf . Acesso em: 06 out 2010 .

2010. Censo Agropecuário 2006. Disponível em: http://www.ibge.gov.br/ cidadesat/topwindow.htm?1.Acesso em 30 out 2010.

Lima, J. R. O., R. B. Silva, L.B. Caland, L.S.S. Santos, C. V. R. Moura, \& E. M. Moura. 2001. Biodiesel de óleo de tucum (Astrocaryum vulgare) extraído artesanalmente sintetizado via etilica. 2001. Disponível em: http://sec.sbq. org.br/cd29ra/resumos/T1840-1.pdf. Acesso em 01 jun 2013.

Lima, R. R., L. C. Trassato \& V. Coelho. 1986. O tucumã (Astrocaryum vulgare Mart.). Principais características e potencialidade agroindustrial. Boletim de Pesquisa 75. Belém: EMBRAPA-CPATU.

Lleras, E., D. C. Giacometti \& L. Coradin. 1983. Áreas criticas de distribución de palmas em las Americas para colecta, evaluación y conservación, in Informe de la reunión de consulta sobre palmeras poco utilizadas de América Tropical. Organizado por CATIE/ FAO, pp. 67-101. Turrialba: FAO.

Miranda, I.P.A. \& A. Rabelo. 2008. Guia de identificação das palmeiras de Porto Trombetas - PA. Manaus: Editora da Universidade Federal do Amazonas/Instituto Nacional de Pesquisas da Amazonia. $365 p$. 
Nahum, J. S. 2011. De Ribeirinha a Quilombola: dinâmica territorial de comunidades rurais na Amazônia paraense. Campo - Território: Revista de Geografia Agrária 6(12):79-103.

Oliveira, J. S. R.; R. O. Kato; T.F. Oliveira; J. Queiroz \& R. Cardoso. 2007. Agricultura familiar e SAFs: Produção com conservação na Amazônia Oriental, nordeste paraense. Belém: Universidade Federal Rural da Amazônia - UFRA. Disponível em: <www.cnpat. embrapa.br/sbsp/anais/Trab_Format_ PDF/53.pdf>. Acesso em: 20 jan 2011.

Pereira, K.J.C.; B.F. Lima; R. S. Reis \& E. A. Veasey. 2006. Saber tradicional, agricultura e transformação da paisagem na Reserva de Desenvolvimento Sustentável Amanã, Amazonas. UAKARI 2(1): 9-26.

Pesce, S. 2009. Oleaginosas da Amazônia. Belém: Museu Paraense Emílio Goeldi. Brasília: Ministério do Desenvolvimento Agrário.

Rogerio, J.B.; I.D. Duarte; R. Antoniassi; H. R. Bizzo \& N. T. V. Junqueira. 2010. Rendimento em óleo e composição em ácidos graxos de frutos de tucumã coletados no Estado do Mato Grosso. $4^{\circ}$ Congresso da Rede Brasileira de Tecnologia de Biodiesel. $7^{\circ}$ Congresso Brasileiro de Plantas Oleaginosas, Óleos, Gorduras e Biodiesel. Belo Horizonte.

Sampaio, C. A.; O. R.Kato \& D. Nascimento-e-Silva. 2008. Sistema de corte e trituração da capoeira sem queima como alternativa de uso da terra, rumo à sustentabilidade florestal no nordeste paraense. Revista de gestão social e ambiental 2(1): 41-53.

Schwartz, G. 2007. Manejo sustentável de florestas secundárias: espécies potenciais no nordeste do Pará, Brasil. Amazốnia: Companbia \& Desenvolvimento 3(5): 125-147.
Valente, M. A., T.E. Rodrigues; J. M. L. Silva; P. L. dos Santos; E. J. M. Carvalho; J. R. Gama; P. A. M. Rollim; E. S. Silva; I. C. B. Pereira. 2001. Solos e Aptidão agrícola das terras do município de Irituia. Belém: Embrapa Oriental.

Recebido em: 13/06/2013.

Aprovado em: 31/07/2013. 